\title{
The Structure of the Violence to Medical Staff and its Personality Correlates in Two Age-Different Adult Samples in China
}

Fan $\mathbf{H}^{1}$, Wang $\mathbf{M}^{2}$, Shao $\mathbf{X}^{1}$, Jia $\mathbf{Y}^{1}$, Wang $\mathrm{C}^{1}$ and Wang $\mathbf{W}^{1 *}$

${ }^{1}$ Department of Clinical Psychology and Psychiatry/School of Public Health, Zhejiang University College of Medicine, Hangzhou, China

${ }^{2}$ Faculty of Psychology, Complutense University of Madrid, Madrid, Spain

\begin{abstract}
Background: In order to know the structure of the violence to medical staff and its personality correlates, we designed two studies in Chinese university students and the relatives of patients consulting comprehensive hospitals. Methods: First, we invited 457 participants to answer a 68-item matrix measuring the violence to medical staff, and their answers were dealt with both exploratory and confirmatory factor analyses. Second, 118 participants aged 18-20 years old (Younger) and 118 aged 26-45 (Older) were tested with the VMSQ, the Parker Personality Measure, and the Plutchik - van Praag Depression Inventory.
\end{abstract}

Results: A structure-validated Violence to Medical Staff Questionnaire (VMSQ) was developed with 34 items under seven scales. The Older scored significantly higher than the Younger did on VMSQ Violence terminator, Physical abuse initiator, and Verbal abuse initiator, but lower on Sympathy to victims and Knowledge of violence, and on Schizotypal, Avoidant, and Dependent personality disorder functioning styles. In Younger, Paranoid predicted the Verbal abuse initiator, Schizotypal the Physical abuse initiator, Antisocial the Violence terminator, Borderline the Sympathy to victims, Avoidant the Physical abuse initiator, and Dependent the Sympathy to victims; in Older, PassiveAggressive the Physical abuse initiator, Narcissistic the Dissatisfaction with service, and Obsessive-Compulsive the Sympathy to victims.

Conclusion: We developed a structure-validated questionnaire to measure the violence, and found that personality features were associated with different violence structures in two different age groups, which might help to prevent medical staff from violence in medical settings.

Keywords: Adulthood; Depression; Personality; Violence to medical staff

\section{Abbreviations}

VMSQ: Violence to Medical Staff Questionnaire; PERM: Parker Personality Measure; PVP: Plutchik-Van Praag Depression Inventory

\section{Introduction}

The violence to medical staff is an occupational hazard in hospitals or other health providers [1], and is also a substantial problem for patients and governments [2-4]. In the workplace, the injury is not only physical but also psychological [5]. The obvious consequence of the violence is the shortage of medical staff and the reduction in quality of health services [6]. The violence to medical staff happens all over the world including China, for example, 76\% nurses reported abuse at work in Hong Kong, China [7]. There were 101 medical violence events resulting in death or injuries that occurred in most provinces and cities of China from 2003 to 2013, with a rapid increase for the last 3 years [8]. The violence frequency was high [9] and the job satisfaction of Chinese medical staff relating to the violence was low [10], which called for protection from government and hospital [11].

Many scholars have contributed to the mechanisms and prevention of the violence to medical staff, one crucial step of which is to characterize the structure and aetiology of the violence. There are some specific inventories measuring violence in occupation, most of which were developed as surveys on victims such as health care workers who had suffered from violence or abuse. For instance, a questionnaire was developed to determine the prevalence and the possible risk factors of workplace violence at medical institutions [6,12]. Items in the questionnaire cover both physical and psychological violence including the verbal abuse, bullying/mobbing, sexual and racial harassment experienced annually by the health care workers. Other investigators also measured the violence experience of individual staff, using a simple question "Have you ever been a victim of violence or threat of violence at your workplace/at work during the past year?" [2]. In addition, a semi-structured violence questionnaire was developed to explore the prevalence of physical assault, threat, and verbal abuse to medical staff members in a general hospital setting [13]. However, up to present, there is no structure-validated questionnaire to measure the violence to medical staff.

In the current study, we would like to develop a comprehensive measure which covers various violence aspects. For instance, the first aspect is the physical violence, which is reflected by behaviors such as stabbing, spitting, punching, slapping, or kicking with the intent of causing bodily harm $[14,15]$. The second is the psychological violence, which contains the threat, bullying, mobbing behavior in front of staff or patients [16]. The third is the verbally vindictive, cruel, or malicious attempts to humiliate or undermine a medical staff $[6,17]$. The fourth is the knowledge or attitude toward the violence to medical staff, which includes the dissatisfaction with medical service and sympathy towards medical staff during violence [18]. The fifth is the cause of violence,

*Corresponding author: Wang W, Department of Clinical Psychology and Psychiatry/School of Public Health, Zhejiang University College of Medicine, Yuhangtang Road 866, Hangzhou, Zhejiang 310058, China, Tel/Fax: +86-571-88208188; E-mail: drwangwei@zju.edu.cn

Received: June 04, 2019; Accepted: June 19, 2019; Published: June 26, 2019

Citation: Fan H, Wang M, Shao X, Jia Y, Wang C, et al. (2019) The Structure of the Violence to Medical Staff and its Personality Correlates in Two Age-Different Adult Samples in China. J Psychiatry 22: 465. doi: 10.35248/2378-5756.19.22.465

Copyright: (c) 2019 Fan $\mathrm{H}$, et al. This is an open-access article distributed under the terms of the Creative Commons Attribution License, which permits unrestricted use, distribution, and reproduction in any medium, provided the original author and source are credited 
which includes various elements in eliciting unpleasant feelings and hostile/aggressive thoughts of people about violent behavior [19]. Therefore, our first hypothesis is that the measure at least covers the above-mentioned five aspects.

Regarding factors influencing the violence against medical staff, age factor is often considered since it is involved in crime. After reviewing ninety studies of homicide, assault, robbery, rape, etc., scholars found only a few studies consistently showing the significant relationship between age and crime [20]. Some studies however, have shown a sharp rise with the onset of adolescence followed by a steady decline with age during the criminal activities, and the prime ages of criminal involvement were roughly 15-24 years [21]. The inconsistency might be resulted from different age involvements in different studies. For instance, the youth defined by United Nations is in ages 15-24 years [22], and most people aged 18-20 are university students in China. People of these ages might behave differently from those of 26-45 years who were confronted with more problems from other aspects of life, while people of 45 years or Older were less involved in crimes [23]. Thus, our second hypothesis is that the violence against medical staff presents distinct features in different age groups, for instance in Younger (18-20 years) $v s$. Older (26-45 years) adult populations.

Furthermore, there was an association between violence and personality disorders such as the paranoid, schizoid, antisocial, narcissistic, borderline, avoidant, dependent, histrionic, passiveaggressive, and obsessive-compulsive types [24]. Individuals engaging in violent and nonviolent offence or aggression were more likely to meet diagnosis for a personality disorder [25]. The risk of violence was recognized in terms of impulsive control, affect regulation, narcissism, antisocial, and paranoid personality disorders [26]. The borderline personality disorder was linked with violence, which could be due to its unstable and intense interpersonal relationships, impulsivity, intense anger, and affective instability [27]. Thereupon, our third hypothesis is that paranoid, antisocial, borderline, narcissistic, dependent, obsessivecompulsive, and passive-aggressive types of personality disorder are associated with the violence against medical staff.

Hence, we designed two studies in the present project to test our three hypotheses. In study 1 , we invited participants to answer a 68 -item MATRIX measuring the violence to medical staff. Their answers could help us to develop a structure-validated questionnaire measuring this violence. In study 2 , we invited both Younger and Older participants to answer the putative questionnaire, and the Parker Personality Measure (PERM) [28] assessing personality disorder functioning styles, and the Plutchik-van Praag Depression Inventory (PVP)[29] assessing depressive mood since depression was associated with the impulsive violence [30].

\section{Materials and Methods}

\section{Study 1: Measurement structure of violence to medical staff}

Participants: Four hundred and fifty seven healthy participants (233 women, mean age 23.82 years with 6.09 S.D, range 18-64 years; 224 men, mean age $25.02 \pm 6.01$, range 19-51) were recruited from university students, community members or the accompanying relatives of in/out patients consulting doctors in comprehensive hospitals. All participants enrolled in the present study had received no less than nine years of compulsory education in China. An experienced psychiatrist (WW) ensured that they did not suffer from any neuropsychiatric disorders, and were free from alcohol, tobacco or substance abuse, through a brief, semi-structured interview. The study was approved by the Ethics Committee of Zhejiang University School of Public Health (No. ZGL201307-2-8), and conformed to the Helsinki Declaration concerning human rights, and followed correct procedures concerning treatment of humans in research. All participants gave their written informed consents to participate.

The item-matrix: In a quiet room, participants were asked to complete the 68-item MATRIX, which were pooled together to measure the violence to medical staff in five aspects: the physical violence to, psychological violence to, and verbal abuse to medical staff, the knowledge or attitude toward, and the cause of the violence. A five-point Likert rating scale was chosen for the questionnaire: 1-very unlike me, 2-moderately unlike me, 3-somewhat like and unlike me, 4-moderately like me, and 5-very like me.

Statistical analyses: Answers to the 68 items from 457 participants were submitted to the principal component analysis, using the SPSS statistical software (v19.0; IBM Corp., 2010, Somers, NY). The factor loadings were rotated orthogonally using the varimax normalized method. Items which were loaded less heavily (loadings $\leq 0.40$ ) on a target factor, or cross-loaded heavily (cross-loadings $\geq 0.35$ ) on more than one factor were removed from subsequent analyses, one-byone. The procedure continued until no further item was needed to be removed.

Afterwards, the fit of the latent factors was evaluated by the confirmatory factor analysis for structural equation modeling using Analysis of Moment Structures (AMOS; v17.0; AMOS Development Corp., 2008, Crawfordville, FL). Later, a model fit based on the latent factors and remaining items was established, a structure-validated questionnaire was formed, and the internal reliabilities (the Cronbach alphas) of each latent factor were calculated, and then gender effects on these factors (scales) were computed. The Student $t$ test plus Bonferroni's correction were applied to all scale scores of the violence questionnaire in two genders. A p value less than 0.05 was considered to be significant.

Results: The principal component analysis extracted 13 factors with eigenvalues larger than 1.0. The screen plot and parallel analysis results suggested a seven-factor solution, and the first seven factors with eigenvalues of $10.96,7.48,6.98,6.98,6.97,5.25$, and 3.96 , which accounted for $48.57 \%$ of the total variance. Thirty-four items were retained using the target-loading of 0.40 and cross-loading of 0.35 as criteria (Table 1). Using the seven factors and related items, we formed a fitting model, with satisfactory parameter values (Figure 1).

The first factor has five items, e.g., "If I had a physical conflict with medical staff, I'd beat him/her until I was forced to stop under constraint", which describes terminators of physical assault. The second factor with five items, e.g., "When consulting a doctor, if my needs weren't met, I'd stick a knife to medical staff", describes the initiator of physical abuse. The third factor with five items, e.g., "When consulting a doctor, if medical staff treated me perfunctorily and half-heartedly, I'd scold him/her", characterizes the initiator of verbal abuse. The fourth factor with six items, e.g., "My relatives often express their dissatisfaction with medical staff", describes the dissatisfaction with medical staff.

The fifth factor with five items, e.g., "I'm very sympathetic with medical staff victimized by physical violence", depicts the sympathy for medical staff suffering from violence. The sixth factor with four items, e.g., "I think it counts as violence to medical staff that patients or their relatives threaten medical staff verbally", depicts the knowledge of violence to medical staff. The seventh factor with four items, e.g., "When consulting a doctor, if I saw someone attacking medical staff, 
Citation: Fan H, Wang M, Shao X, Jia Y, Wang C, et al. (2019) The Structure of the Violence to Medical Staff and its Personality Correlates in Two Age-Different Adult Samples in China. J Psychiatry 22: 465. doi: 10.35248/2378-5756.19.22.465

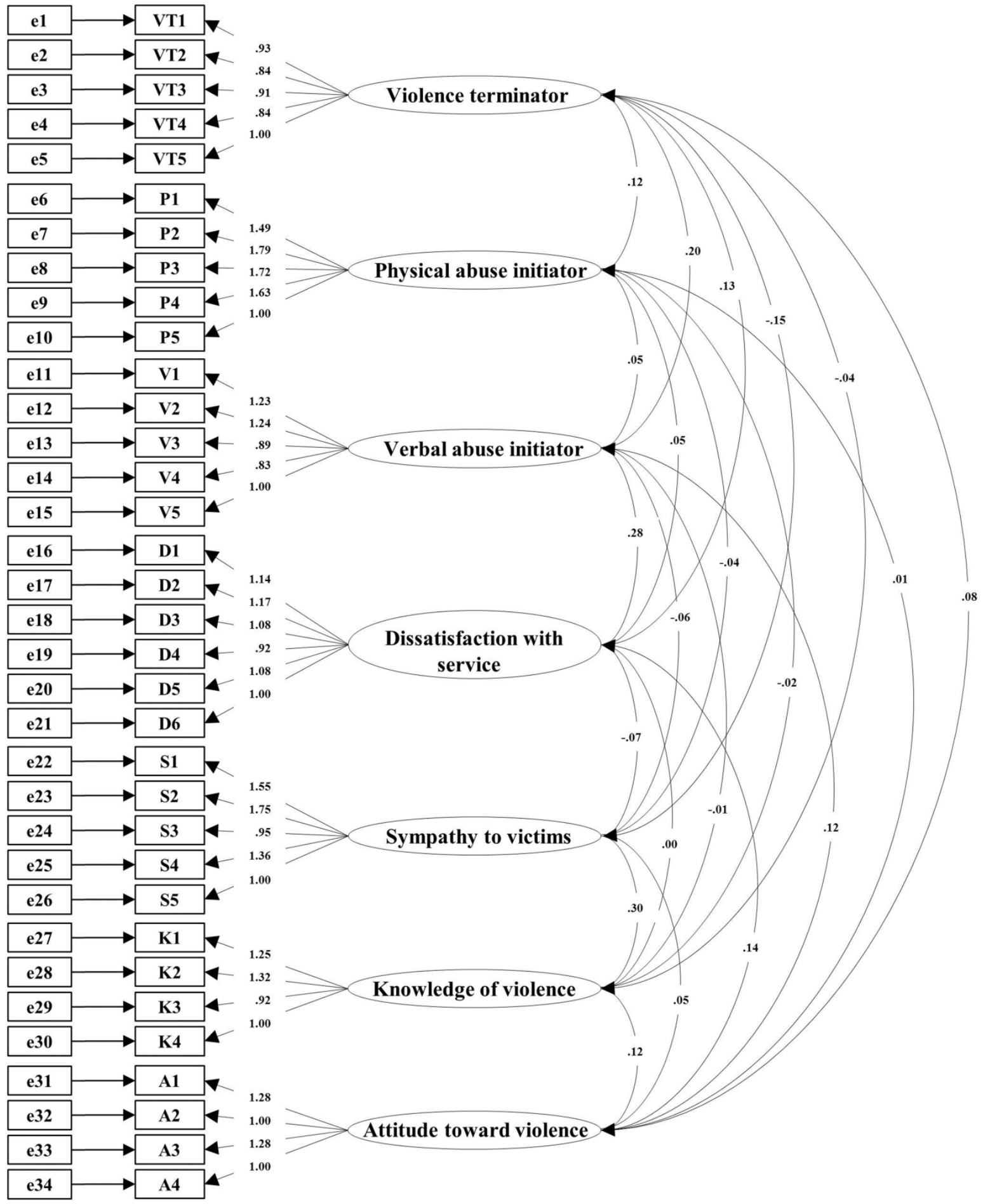

Figure 1: Standardized seven-factor structure of the Violence to Medical Staff Questionnaire (VMSQ) in 457 participants. Model fitting indices: the $X^{2} / \mathrm{df}, 2.37$; the goodness of fit index, 0.86; the adjusted goodness of fit index, 0.84; the Tucker-Lewis index, 0.88; the comparative fit index, 0.89 ; the root mean square error of approximation, 0.055; and the standardized root mean square residual, 0.059 .

I'd criticize him/ her aside rather than step forward to stop him/her", describes the attitude towards the violence.

The above factors were named as violence terminator, physical abuse initiator, verbal abuse initiator, dissatisfaction with service, sympathy to victims, knowledge of violence, and attitude toward violence respectively, each with a satisfactory internal reliability in two gender groups (Table 2). Men scored significantly higher on the violence 
Citation: Fan H, Wang M, Shao X, Jia Y, Wang C, et al. (2019) The Structure of the Violence to Medical Staff and its Personality Correlates in Two Age-Different Adult Samples in China. J Psychiatry 22: 465. doi: 10.35248/2378-5756.19.22.465

Page 4 of 8

\section{Violence terminator}

If I had a physical conflict with medical staff, l'd beat him/her until I was forced to stop under constraint.

\begin{tabular}{|c|c|c|c|c|c|c|c|} 
Factor 1 & $\mathbf{2}$ & $\mathbf{3}$ & $\mathbf{4}$ & $\mathbf{5}$ & $\mathbf{6}$ & $\mathbf{7}$ \\
\hline $\mathbf{0 . 8 5}$ & 0.18 & 0.04 & 0.05 & -0.04 & -0.07 & 0.05 \\
\hline $\mathbf{0 . 8 3}$ & 0.26 & 0.12 & 0.09 & -0.08 & 0.01 & 0.06 \\
\hline $\mathbf{0 . 8 0}$ & 0.17 & 0.16 & 0.00 & -0.13 & -0.01 & 0.11 \\
\hline $\mathbf{0 . 7 8}$ & 0.32 & 0.10 & 0.09 & -0.09 & -0.01 & 0.01 \\
\hline $\mathbf{0 . 7 6}$ & 0.20 & 0.15 & 0.06 & -0.13 & 0.03 & 0.05 \\
\hline
\end{tabular}

If I had a physical conflict with medical staff, l'd beat him/her until he/she asked for forgiveness.

If I had a physical conflict with medical staff, I'd beat him/her until I cooled down.

If I had a physical conflict with medical staff, l'd beat him/her into a coma

If I had a physical conflict with medical staff, I'd beat him/her until he/she couldn't get up.

$\begin{array}{llllllll}\mathbf{0} & .76 & 0.20 & 0.15 & 0.06 & -0.13 & 0.03 & 0.05\end{array}$

\section{Physical abuse initiator}

If I was irritated by medical staff, l'd attack him/her on the vital parts with a sharp tool such as a knife.

\begin{tabular}{l|l|l|l|l|l|l}
0.28 & $\mathbf{0 . 8 1}$ & 0.05 & 0.13 & -0.06 & -0.04 & 0.00
\end{tabular}

When consulting a doctor, if my needs weren't met, l'd stick a knife to medical staff.

If I had a physical conflict with medical staff, l'd beat him/her to death.

If I didn't get better after treatment, l'd beat medical staff.

When consulting a doctor, if I saw people beating medical staff, I'd join them.

\begin{tabular}{l|l|l|l|l|l|l}
0.11 & $\mathbf{0 . 8 1}$ & 0.05 & 0.08 & -0.03 & -0.02 & 0.00
\end{tabular}

\begin{tabular}{l|l|l|l|l|l|l|}
0.24 & $\mathbf{0 . 7 6}$ & 0.00 & 0.13 & -0.06 & 0.00 & -0.05 \\
\hline
\end{tabular}

\begin{tabular}{l|l|l|l|l|l|l|}
0.27 & $\mathbf{0 . 6 4}$ & 0.21 & 0.04 & -0.19 & 0.04 & 0.04
\end{tabular}

\begin{tabular}{l|l|l|l|l|l|l}
0.29 & $\mathbf{0 . 5 8}$ & 0.07 & 0.08 & -0.13 & -0.06 & 0.06
\end{tabular}

\section{Verbal abuse initiator}

When consulting a doctor, if medical staff treated me perfunctorily and half-heartedly, l'd scold him/her.

When consulting a doctor, if medical staff shouted at me impolitely, l'd scold him/her.

When consulting a doctor, if my needs weren't met, l'd scold medical staff.

If my condition got worse after treatment, l'd scold medical staff.

When consulting a doctor, if medical staff treated me impatiently, l'd scold him/her.

\section{Dissatisfaction with service}

My relatives often express their dissatisfaction with medical staff.

In my view, medical staff nowadays aren't concerned about patients wholeheartedly.

In my view, medical staff nowadays are insufficient in expertise.

I often express my dissatisfaction with medical staff to my relatives or friends.

My friends often express their dissatisfaction with medical staff.

In my view, medical staff's service attitude nowadays is unsatisfying.

\begin{tabular}{l|l|l|l|l|l|l|}
0.03 & -0.01 & $\mathbf{0 . 8 4}$ & 0.16 & 0.03 & -0.02 & 0.02 \\
\hline
\end{tabular}

\begin{tabular}{l|l|l|l|l|l|l|}
0.15 & -0.03 & $\mathbf{0 . 7 7}$ & 0.17 & 0.12 & -0.05 & -0.01 \\
\hline
\end{tabular}

\begin{tabular}{l|l|l|l|l|l|l|}
0.16 & 0.12 & $\mathbf{0 . 7 1}$ & 0.18 & -0.15 & 0.04 & 0.10
\end{tabular}

\begin{tabular}{|l|l|l|l|l|l|l|}
0.07 & 0.03 & $\mathbf{0 . 6 7}$ & 0.22 & -0.04 & 0.02 & 0.15 \\
\hline
\end{tabular}

\begin{tabular}{|l|l|l|l|l|l|l|}
0.14 & 0.23 & $\mathbf{0 . 6 5}$ & 0.12 & -0.08 & -0.02 & 0.02 \\
\hline
\end{tabular}

\section{Sympathy to victims}

I'm very sympathetic with medical staff victimized by physical violence.

When seeing reports about violence to medical staff, I truly sympathize with medical staff victimized by violence.

When seeing reports about violence to medical staff, I'm truly angry with the violator(s).

If I couldn't reason with evil-minded medical staff, I'd appeal to law for a solution.

If irritated by medical staff, l'd try to suppress my anger.

\begin{tabular}{l|l|l|l|l|l|l|}
0.08 & 0.03 & 0.14 & $\mathbf{0 . 7 2}$ & -0.12 & 0.05 & 0.08
\end{tabular}

\begin{tabular}{l|l|l|l|l|l|l|}
0.05 & 0.11 & 0.17 & $\mathbf{0 . 7 1}$ & 0.01 & -0.09 & 0.10 \\
\hline
\end{tabular}

\begin{tabular}{l|l|l|l|l|l|l|}
-0.04 & 0.12 & 0.01 & $\mathbf{0 . 6 5}$ & 0.16 & -0.01 & 0.11
\end{tabular}

\begin{tabular}{l|l|l|l|l|l|l|}
0.06 & 0.18 & 0.23 & $\mathbf{0 . 6 4}$ & -0.17 & 0.03 & 0.02 \\
\hline
\end{tabular}

\begin{tabular}{l|l|l|l|l|l|l|}
0.09 & 0.06 & 0.13 & $\mathbf{0 . 6 4}$ & -0.09 & 0.10 & -0.01
\end{tabular}

\begin{tabular}{l|l|l|l|l|l|l}
0.02 & -0.05 & 0.16 & $\mathbf{0 . 6 3}$ & 0.13 & -0.02 & 0.15
\end{tabular}

\section{Knowledge of violence}

I think it counts as violence to medical staff that patients or their relatives threaten medical staff verbally.

I think it counts as violence to medical staff that patients or their relatives slander medical staff.

I think it counts as violence to medical staff that patients or their relatives scold medical staff.

I think it counts as violence to medical staff that patients or their relatives harass medical staff by communication modes.

\begin{tabular}{|c|c|c|c|c|c|c|}
\hline-0.13 & -0.01 & -0.10 & -0.12 & $\mathbf{0 . 7 8}$ & 0.23 & -0.02 \\
\hline-0.19 & -0.12 & -0.02 & -0.11 & $\mathbf{0 . 7 3}$ & 0.28 & -0.03 \\
\hline-0.13 & -0.01 & 0.09 & -0.11 & $\mathbf{0 . 6 3}$ & 0.24 & 0.06 \\
\hline 0.00 & -0.28 & 0.06 & 0.13 & $\mathbf{0 . 6 0}$ & 0.11 & 0.08 \\
\hline-0.04 & -0.08 & -0.16 & 0.16 & $\mathbf{0 . 5 3}$ & 0.18 & 0.13 \\
\hline & & & & & & \\
\hline 0.03 & -0.13 & -0.01 & -0.01 & 0.15 & $\mathbf{0 . 8 2}$ & 0.07 \\
\hline-0.02 & -0.03 & 0.02 & -0.01 & 0.25 & $\mathbf{0 . 7 8}$ & 0.09 \\
\hline 0.03 & -0.01 & 0.00 & 0.04 & 0.21 & $\mathbf{0 . 7 2}$ & -0.07 \\
\hline-0.08 & 0.10 & -0.06 & 0.06 & 0.25 & $\mathbf{0 . 6 8}$ & 0.08 \\
\hline
\end{tabular}

\section{Attitude toward violence}

When consulting a doctor, if I saw someone attacking medical staff, l'd criticize him/her aside rather than step forward to stop him/her.

When consulting a doctor, if I saw someone scolding medical staff, l'd criticize him/her aside rather than step forward to stop him/her.

When consulting a doctor, if I saw someone attacking medical staff, I wouldn't step forward to stop him/her. When consulting a doctor, if I saw someone scolding medical staff, I wouldn't step forward to stop him/her.

\begin{tabular}{|c|c|c|c|c|c|c|}
\hline-0.01 & 0.05 & 0.08 & 0.04 & 0.08 & 0.05 & $\mathbf{0 . 7 7}$ \\
\hline 0.02 & -0.03 & 0.14 & 0.01 & 0.16 & 0.18 & $\mathbf{0 . 7 4}$ \\
\hline 0.14 & -0.07 & -0.08 & 0.17 & -0.06 & -0.03 & $\mathbf{0 . 7 2}$ \\
\hline 0.09 & 0.07 & 0.10 & 0.18 & 0.01 & -0.05 & $\mathbf{0 . 7 1}$ \\
\hline
\end{tabular}

Note: Items with target loading $>0.40$ and cross-loading $<0.35$ were shown; loadings higher than 0.40 are presented in bold for clarity.

Table 1: Item loadings on seven factors in 457 participants. 
Citation: Fan H, Wang M, Shao X, Jia Y, Wang C, et al. (2019) The Structure of the Violence to Medical Staff and its Personality Correlates in Two Age-Different Adult Samples in China. J Psychiatry 22: 465. doi: 10.35248/2378-5756.19.22.465

Page 5 of 8

terminator $(\mathrm{p}<0.001)$, physical abuse initiator $(\mathrm{p}<0.01)$, and verbal abuse initiator $(\mathrm{p}<0.001)$ factors, but lower on the sympathy to victims $(p<0.05)$ factor than women did (Table 2). The questionnaire was then named as the Violence to Medical Staff Questionnaire (VMSQ).

\section{Study 2: Factors associating with violence to medical staff}

Participants: We recruited 236 participants from university students, community members or the accompanying relatives of in/out-patients consulting doctors in comprehensive hospitals. They were grouped into the (1) Younger group (Younger, $n=118 ; 60$ women, 58 men; mean age, 19.92 years with 0.31 S.D, age range, $18-20$ years; 116 unmarried, 2 undisclosed), and (2) Older group (Older; $n=118 ; 67$ women, 51 men; mean age, $32.40 \pm 4.97$, range, $26-45$ years; 30 unmarried, 82 married, 1 divorced, 5 undisclosed). No gender distribution difference was found between the two groups $\left(\chi^{2}(1,234)=1.38, p=0.24\right)$. All participants had received no less than nine years of compulsory education in China, did not suffer from any neuropsychiatric disorders, and were free from alcohol, tobacco or substance abuse, through a brief, semi-structured interview by an experienced psychiatrist (WW).
Instruments: In a quiet room, participants were asked to complete three questionnaires as described below. The internal reliabilities of all scales in the current study were shown in Table 3.

A. The Parker Personality Measure (PERM) [28] measures 11 functioning styles of paranoid, schizoid, schizotypal, antisocial, borderline, histrionic, narcissistic, avoidant, dependent, obsessivecompulsive, and passive-aggressive personality disorders. Each PERM item has the same five-point Likert scale as used in the matrix of 68 items (Study 1).

B. The Plutchik-van Praag Depression Inventory (PVP) [29] contains 34 items. Each PVP item has a three-point scale $(0,1,2)$, which corresponds to depressive tendencies. Participants have "possible depression" if they score between 20 and 25, or "depression" if they score higher than 25 .

C. The Violence to Medical Staff Questionnaire (VMSQ, from Study 1) contains 34 items measuring the Violence terminator, Physical abuse initiator, Verbal abuse initiator, Dissatisfaction with service, Sympathy to victims, Knowledge of violence, and Attitude toward

\begin{tabular}{|c|c|c|c|c|c|}
\hline \multirow{2}{*}{ VMSQ } & \multicolumn{2}{|c|}{ Women $(n=233)$} & \multicolumn{2}{|c|}{ Men $(n=224)$} & \multirow{2}{*}{ 95\% Confidence Interva } \\
\hline & Alpha & Score & Alpha & Score & \\
\hline Violence terminator & 0.89 & $5.84 \pm 2.62$ & 0.90 & $7.50 \pm 4.30^{*}$ & $1.01 \sim 2.32$ \\
\hline Physical abuse initiator & 0.77 & $5.40 \pm 1.52$ & 0.87 & $6.02 \pm 2.45^{*}$ & $0.24 \sim 1.00$ \\
\hline Verbal abuse initiator & 0.79 & $9.64 \pm 4.07$ & 0.78 & $11.22 \pm 4.81^{*}$ & $0.76 \sim 2.40$ \\
\hline Dissatisfaction with service & 0.80 & $13.75 \pm 4.82$ & 0.84 & $14.22 \pm 5.02$ & $-0.43 \sim 1.38$ \\
\hline Sympathy to victims & 0.79 & $19.94 \pm 3.97$ & 0.80 & $18.97 \pm 4.48^{*}$ & $-1.75 \sim-0.19$ \\
\hline Knowledge of violence & 0.62 & $13.67 \pm 4.36$ & 0.68 & $13.03 \pm 4.49$ & $-1.45 \sim 0.18$ \\
\hline Attitude toward violence & 0.80 & $10.58 \pm 3.88$ & 0.69 & $10.28 \pm 3.41$ & $-0.97 \sim 0.37$ \\
\hline
\end{tabular}

Table 2: Internal alphas and scale scores (Mean \pm S.D.) of the Violence to Medical Staff Questionnaire (VMSQ) in women and men.

\begin{tabular}{|c|c|c|c|c|c|}
\hline & \multicolumn{2}{|c|}{ YOUNGER $(n=118)$} & \multicolumn{2}{|c|}{ OLDER $(n=118)$} & \multirow{2}{*}{ 95\% Confidence Interval } \\
\hline & Alpha & Score & Alpha & Score & \\
\hline \multicolumn{6}{|c|}{ VMSQ } \\
\hline Violence terminator & 0.86 & $6.28 \pm 2.89$ & 0.91 & $7.76 \pm 4.78^{*}$ & $-2.50 \sim-0.47$ \\
\hline Physical abuse initiator & 0.67 & $5.39 \pm 1.13$ & 0.87 & $6.02 \pm 2.67^{*}$ & $-1.15 \sim-0.10$ \\
\hline Verbal abuse initiator & 0.84 & $9.91 \pm 4.40$ & 0.79 & $11.87 \pm 4.91^{*}$ & $-3.16 \sim-0.77$ \\
\hline Dissatisfaction with service & 0.80 & $13.40 \pm 4.70$ & 0.80 & $14.64 \pm 5.51$ & $-2.55 \sim 0.08$ \\
\hline Sympathy to victims & 0.57 & $20.73 \pm 3.06$ & 0.76 & $17.25 \pm 5.09^{*}$ & $2.40 \sim 4.56$ \\
\hline Knowledge of violence & 0.74 & $14.86 \pm 3.78$ & 0.80 & $11.09 \pm 4.75^{*}$ & $2.67 \sim 4.87$ \\
\hline Attitude toward violence & 0.76 & $10.31 \pm 3.70$ & 0.65 & $10.39 \pm 3.57$ & $-1.02 \sim 0.85$ \\
\hline \multicolumn{6}{|c|}{ PERM } \\
\hline Paranoid & 0.87 & $20.11 \pm 7.09$ & 0.81 & $19.86 \pm 6.63$ & $-1.52 \sim 2.01$ \\
\hline Schizoid & 0.52 & $19.03 \pm 4.53$ & 0.42 & $18.56 \pm 4.10$ & $-.63 \sim 1.58$ \\
\hline Schizotypal & 0.72 & $9.76 \pm 3.68$ & 0.63 & $8.40 \pm 3.17^{*}$ & $0.49 \sim 2.24$ \\
\hline Antisocial & 0.75 & $19.18 \pm 5.59$ & 0.74 & $18.59 \pm 5.86$ & $-0.88 \sim 2.05$ \\
\hline Borderline & 0.80 & $20.07 \pm 6.24$ & 0.77 & $19.10 \pm 6.11$ & $-0.62 \sim 2.55$ \\
\hline Histrionic & 0.62 & $12.56 \pm 3.67$ & 0.66 & $12.18 \pm 4.07$ & $-0.61 \sim 1.38$ \\
\hline Narcissistic & 0.77 & $16.48 \pm 5.07$ & 0.79 & $15.57 \pm 5.42$ & $-0.43 \sim 2.26$ \\
\hline Avoidant & 0.79 & $24.11 \pm 6.45$ & 0.72 & $22.14 \pm 6.28^{*}$ & $0.34 \sim 3.61$ \\
\hline Dependent & 0.80 & $22.54 \pm 6.46$ & 0.75 & $19.89 \pm 5.92^{*}$ & $1.06 \sim 4.24$ \\
\hline Obsessive-Compulsive & 0.59 & $15.85 \pm 3.90$ & 0.62 & $16.80 \pm 4.64$ & $-2.05 \sim 0.15$ \\
\hline Passive-Aggressive & 0.71 & $20.50 \pm 5.51$ & 0.75 & $19.01 \pm 6.00$ & $0.02 \sim 2.97$ \\
\hline PVP & 0.79 & $8.25 \pm 5.45$ & 0.85 & $8.60 \pm 6.53$ & $-1.90 \sim 1.19$ \\
\hline
\end{tabular}

Table 3: Internal alphas and scale scores (Mean \pm S.D) of the Violence to Medical Staff Questionnaire (VMSQ), the Parker Personality Measure (PERM), and the Plutchikvan Praag Depression Inventory (PVP) in the YOUNGER and OLDER groups. 
Citation: Fan H, Wang M, Shao X, Jia Y, Wang C, et al. (2019) The Structure of the Violence to Medical Staff and its Personality Correlates in Two Age-Different Adult Samples in China. J Psychiatry 22: 465. doi: 10.35248/2378-5756.19.22.465

violence. Each VMSQ item has the same five-point Likert scale as used in the matrix of 68 items (Study 1).

Statistical analyses: The Student $t$ test plus Bonferroni's correction were employed to evaluate between-group differences of each PERM, PVP and VMSQ scale. The multiple linear regression analysis (stepwise method) was applied to search for the relationships between the violence questionnaire and PERM scales, taking PERM scales as potential predictors for the violence scales. A p-value less than 0.05 was considered to be significant.

Results: There was no significant difference of PVP scores between the two groups. The Older group cored significantly higher on VMSQ violence terminator $(\mathrm{t}(1,234)=-2.88, \mathrm{p}<0.01)$, Physical abuse initiator $(\mathrm{t}=-2.35, \mathrm{p}<0.05)$, and Verbal abuse initiator $(\mathrm{t}=-3.24, \mathrm{p}<0.01)$, but lower on the Sympathy to victims $(t=6.37, \mathrm{p}<0.001)$ and Knowledge of violence $(t=6.74, p<0.001)$ scales than the Younger did. The Older scored significantly lower than the Younger did on PERM Schizotypal $(\mathrm{t}(1,234)=3.06, \mathrm{p}<0.01)$, Avoidant $(\mathrm{t}=2.38, \mathrm{p}<0.05)$, and Dependent $(\mathrm{t}=3.29, \mathrm{p}<0.01)$ styles (Table 3$)$.

In view of predicting VMSQ scales by the PERM functioning styles, the accounted variances (adjusted R2 values) were ranged from 0.05 to 0.20 in Younger, and from 0.06 to 0.21 in Older (Table 4). In Younger, six PERM predictors were prominent $(|\beta| s>0.30)$ : the Paranoid style predicted the Verbal abuse initiator scale, Schizotypal the Physical abuse initiator, Antisocial the Violence terminator, Borderline the Sympathy to victims (-), Avoidant the Physical abuse initiator (-), and Dependent the Sympathy to victims. In Older, six PERM predictors were prominent $(|\beta| s>0.30)$ : the Paranoid style predicted the Physical abuse initiator scale, Borderline the Violence terminator, Narcissistic the Dissatisfaction with service, Dependent the Violence terminator (-) and the Verbal abuse initiator, Obsessive-Compulsive the Sympathy to victims, and Passive-Aggressive the Physical abuse initiator (-).

\section{Discussion}

In study 1, after both exploratory and confirmatory factor analyses, we have developed a structure-validated self-report questionnaire, the 34-item VMSQ. The questionnaire had seven scales forming satisfactory model fit; each scale had a satisfactory internal reliability, and some scales had clear gender differences. These outcomes supported our first hypothesis. In study 2, Older participants scored higher on the violence terminator, physical abuse initiator, and Verbal abuse initiator, while lower on the sympathy to victims and knowledge of violence than Younger participants did, which confirmed our second hypothesis. Again in study 2, we found strong and robust PERM predictors, such as paranoid, schizotypal, antisocial, borderline, narcissistic, avoidant, dependent, obsessive-compulsive, and passive-aggressive styles in predicting VMSQ scales in the two groups, which confirmed our third hypothesis.

Factors 1 (Violence terminator) and 2 (Physical abuse initiator) were closely connected to physical violence; and factor 3 (Verbal abuse initiator) to psychological violence. Apparently there were considerable physical and psychological violent factors consistent with existing documentation $[6,16]$. Factors 4 (Dissatisfaction with service) and 5 (Sympathy to victims) were related to feeling for medical staff and attitudes to them, which reflected the doctor-patient relationship. Patients often took notice of medical treatment and their doctors [18], and were involved in disputes with the medical staff due to the medical cares they received [31,32]. Factor 6 (Knowledge of violence) reflected individual awareness of the violence, and factor 7 (Attitude toward violence) indicated individual intention of getting involved in the violence progress. These last two factors were connected with factors which contributed to the violence cause [33].

The score differences between Older and Younger found in our study were in line with that Older people tended to have less respect for the dignity and worth of medical staff [6]. However, the discovery was not exactly the same as studies conducted earlier [21] that a sharp rise appeared with the onset of adolescence followed by a steady decline with age. The reason might be that, for most young adults less than 20 , who are college students, academic problem plays a focal role in their daily life; while most adults aged 26-45, ripe for setting down to accomplish more dreams, have much more problems about social interactions and work to settle, which could result in more violence and aggression [34,35].

\begin{tabular}{|c|c|c|c|c|}
\hline & \multicolumn{2}{|c|}{ YOUNGER ( $n=118)$} & \multicolumn{2}{|r|}{ OLDER $(n=118)$} \\
\hline & Adjusted $R^{2}$ & $\beta(B, S E)$, predictors & Adjusted $R^{2}$ & $\beta(B, S E)$, predictors \\
\hline \multirow{3}{*}{ Violence terminator } & \multirow{3}{*}{0.12} & \multirow{3}{*}{$0.36(0.19,0.05)$ Antisocial $^{* *}$} & \multirow{3}{*}{0.21} & $0.28(0.23,0.08)$ Antisocial $^{* *}$ \\
\hline & & & & $0.41(0.32,0.10)$ Borderline ${ }^{* *}$ \\
\hline & & & & $-0.30(-0.24,0.10)$ Dependent* ${ }^{*}$ \\
\hline \multirow{4}{*}{ Physical abuse initiator } & \multirow{4}{*}{0.20} & $0.43(0.13,0.03)$ Schizotypal ${ }^{* *}$ & \multirow{4}{*}{0.18} & $0.45(0.18,0.05)$ Paranoid $^{* *}$ \\
\hline & & $-0.33(-0.06,0.02)$ Avoidant ${ }^{\star \star}$ & & $-0.34(-0.15,0.05)$ Passive-Aggressive ${ }^{* *}$ \\
\hline & & 027 (004 002 ) Paranoid* & & $-0.24(-0.14,0.06)$ Obsessive-Compulsive ${ }^{*}$ \\
\hline & & 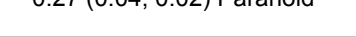 & & $0.26(0.12,0.05)$ Borderline* \\
\hline \multirow{2}{*}{ Verbal abuse initiator } & \multirow{2}{*}{0.14} & \multirow{2}{*}{$0.38(0.24,0.05)$ Paranoid ${ }^{* *}$} & \multirow{2}{*}{0.19} & $0.33(0.28,0.07)$ Dependent ${ }^{* *}$ \\
\hline & & & & $0.24(0.25,0.09)$ Obsessive-Compulsive ${ }^{* *}$ \\
\hline Dissatisfaction with service & 0.06 & $0.26(0.19,0.07)$ Avoidant** & 0.08 & $0.30(0.30,0.09)$ Narcissistic $^{\star *}$ \\
\hline \multirow{2}{*}{ Sympathy to victims } & \multirow{2}{*}{0.11} & $-0.41(-0.20,0.05)$ Borderline ${ }^{* *}$ & \multirow{2}{*}{0.10} & $0.32(0.35,0.10)$ Obsessive-Compulsive ${ }^{* *}$ \\
\hline & & $0.31(0.15,0.05)$ Dependent ${ }^{\star *}$ & & $-0.19(-0.17,0.08)$ Antisocial $^{*}$ \\
\hline Knowledge of violence & - & - & 0.06 & $0.26(0.27,0.09)$ Obsessive-Compulsive ${ }^{* *}$ \\
\hline \multirow{2}{*}{ Attitude toward violence } & \multirow{2}{*}{0.05} & \multirow{2}{*}{$0.24(0.14,0.05)$ Avoidant $^{* *}$} & \multirow{2}{*}{0.10} & $0.26(0.23,0.08)$ Schizoid $^{* *}$ \\
\hline & & & & $0.18(0.11,0.05)$ Passive-Aggressive* \\
\hline
\end{tabular}

Note: ${ }^{*} p<0.05,{ }^{*}{ }^{*} p<0.01 ;|\beta| s$ valued larger than 0.30 were bolded for clarity.

Table 4: Stepwise multiple regressions predicting the Violence to Medical Staff Questionnaire (VMSQ) factors by the Parker Personality Measure (PERM) styles in the YOUNGER and OLDER groups. 
Citation: Fan H, Wang M, Shao X, Jia Y, Wang C, et al. (2019) The Structure of the Violence to Medical Staff and its Personality Correlates in Two Age-Different Adult Samples in China. J Psychiatry 22: 465. doi: 10.35248/2378-5756.19.22.465

The Older scored lower on PERM Schizotypal, Avoidant, and Dependent styles, which was consistent with a longitudinal study [36] showing that personality disorder traits significantly declined with age, specifically, the group of age 25-28 lower than 17-20 on these four traits. Investigations on personality disorders have illustrated the tendency to be moderately stable and to diminish gradually within adolescents [37,38], university students [39] and adults [40]. The associations between PERM and VMSQ scales in both groups were in congruent with the relationships found between violent behavior and personality disorders in general violence $[25,26]$.

It should be noted that our current study design suffered from several limitations. First, the financial information of participants was not noted, since the income status affected violence. Second, our participants were in ages of 18-20 and 26-45; thus, results obtained in these age groups might not be generalized to a broader age population. Third, participants' experience relevant to the violence to medical staff was not noted either, it remains unknown whether the experience is involved in behavior. Fourth, our results were based on normal population, and whether they would be valid in psychiatric patients remains to be seen. Moreover, besides age factor, other confounders such as participants' marital statuses and occupations should also be noted, since they are connected with the violence behavior [41,42]. Nonetheless, we have developed a structure-validated questionnaire to measure the violence to medical staff, and found that personality features were associated with the violence. Our results call for further designs to protect medical staff from injuries, and might help to characterize individuals highly-susceptible to committing crime.

\section{Conclusion}

Our two series of study have demonstrated a structure-validated violence to medical staff questionnaire, and found that two different age groups might have different characteristics on Violence terminator, Physical abuse initiator, Verbal abuse initiator, Sympathy to victims, and Knowledge of violence scales. Furthermore, personality features were associated with different violence structures in groups, indicating that VMSQ might be conductive to preventing medical staff from violence in medical settings.

\section{Acknowledgements}

The study was supported by a grant from the Natural Science Foundation of China (No. 81771475) to the correspondent author (Dr. W. Wang).

\section{Declaration of Interest}

Regarding research work described in the paper, each one of our co-authors, Hongying Fan, Mufan Wang, Xu Shao, Yanli Jia, Chu Wang, and Wei Wang, declares that there is no conflict of interest.

\section{Authors' Contribution}

Hongying FAN, Mufan WANG, Xu SHAO, Yanli JIA, and Chu WANG conducted the tests. Wei WANG conceived the study and participated in the design and coordination of the study. HF and WW drafted the manuscript. All authors read and approved the final manuscript.

\section{References}

1. Centers for Disease Control and Prevention (2002) Violence occupational hazards in hospitals. National Institute for Occupational Safety and Health (NIOSH), Cincinnati.

2. Arnetz JE, Arnetz BB (2001) Violence towards health care staff and possible effects on the quality of patient care. Soc Sci Med 52: 417-427.

3. Hesketh T, Wu D, Mao L, Ma N (2012) Violence against doctors in China. BMJ 345: e5730.
4. Li Z, Yan CM, Shi L, Mu HT, Li X, et al. (2017) Workplace violence against medical staff of Chinese children's hospitals: A cross-sectional study. PloS One 12: e0179373.

5. Wilkinson CW (2003) The role of the occupational health professional in preventing workplace violence. Clin Occup Environ Med 3:855-863.

6. International Labor Organization (ILO), International Council of Nurses (ICN), World Health Organization (WHO), Public Services International (PSI) (2002) Framework guidelines for addressing workplace violence in the health sector. ILO/ICN/WHO/PSI Joint Programme on Workplace Violence in Health Sector. Geneva, Switzerland.

7. Kwok RPW, Law YK, Li KE, Ng YC, Cheung MH, et al. (2006) Prevalence of workplace violence against nurses in Hong Kong. Hong Kong Med J 12: 6-9.

8. Pan $\mathrm{Y}$, Yang $\mathrm{XH}$, He JP, Gu YH, Zhan XL, et al. (2015) To be or not to be doctor, that is the question: a review of serious incidents of violence against doctors in China from 2003-2013. J Public Health 23: 111-116.

9. Wu S, Zhu W, Li H, Lin S, Chai W, et al. (2012) Workplace violence and influencing factors among medical professionals in China. Am J Ind Med 55: 1000-1008.

10. Wu D, Wang Y, Lam KF, Hesketh T (2014) Health system reforms, violence against doctors and job satisfaction in the medical profession: A cross-sectional survey in Zhejiang Province, Eastern China. BMJ Open 4: e006431.

11. Yao S, Zeng Q, Peng M, Ren S, Chen G, et al. (2014) Stop violence against medical workers in China. J Thorac Dis 6: e141-145.

12. Chen WC, Hwu HG, Kung SM, Chiu HJ, Wang JD (2008) Prevalence and determinants of workplace violence of health care workers in a psychiatric hospital in Taiwan. J Occup Health 50: 288-293.

13. Whittington R, Shuttleworth S, Hill L (1996) Violence to staff in a general hospital setting. J Adv Nurs 24: 326-333.

14. Farrell GA, Bobrowski C, Bobrowski $P$ (2006) Scoping workplace aggression in nursing: Findings from an Australian study. J Adv Nurs 55: 778-787.

15. Boyle M, Koritsas S, Coles J, Stanley J (2007) A pilot study of workplace violence towards paramedics. Emerg Med J 24: 760-763.

16. Merecz D, Rymaszewska J, Mościcka A, Kiejna A, Jarosz-Nowak J (2006) Violence at the workplace--questionnaire survey of nurses. Eur Psychiatry 21: 442-450.

17. Farrell GA (1999) Aggression in clinical settings: Nurses' views-a follow-up study. J Adv Nurs 29: 532-541.

18. Hao H, Zhang K, Wang W, Gao G (2017) A tale of two countries: International comparison of online doctor reviews between China and the United States. Int J Med Inform 99: 37-44.

19. Neuman JH, Baron RA (1998) Workplace violence and workplace aggression: Evidence concerning specific forms, potential causes, and preferred targets. J Manag 24: 391-419.

20. Marvell TB, Moody CE (1991) Age structure and crime rates: The conflicting evidence. J Quant Criminol 7: 237-273.

21. Levitt SD (1999) The limited role of changing age structure in explaining aggregate crime rates. Criminol 37: 581-598.

22. United Nations (2015) Youth population trends and sustainable development POPFACTS, No. 2015/1.

23. Farrington DP (1986) Age and crime. J Crim Justice 7: 189-250.

24. Logan C, Blackburn R (2009) Mental disorder in violent women in secure settings: Potential relevance to risk for future violence. Int J Law Psychiatry 32: $31-38$.

25. Gilbert F, Daffern M (2011) Illuminating the relationship between personality disorder and violence: Contributions of the General Aggression Model. Psychol Violence 1: 230-244.

26. Nestor PG (2002) Mental disorder and violence: personality dimensions and clinical features. Am J Psychiatry 159: 1973-1978.

27. Raine A (1993) Features of borderline personality and violence. J Clin Psycho 49: $277-281$.

28. Parker G, Hadzi-Pavlovic D (2001) A question of style: Refining the dimensions of personality disorders style. J Pers Disord 15: 300-318. 
Citation: Fan H, Wang M, Shao X, Jia Y, Wang C, et al. (2019) The Structure of the Violence to Medical Staff and its Personality Correlates in Two Age-Different Adult Samples in China. J Psychiatry 22: 465. doi: 10.35248/2378-5756.19.22.465

Page 8 of 8

29. Plutchik R, van Praag HM (1987) Interconvertability of five self-reported measures of depression. Psychiatry Res 22: 243-256.

30. Brent DA, Johnson BA, Perper J, Connolly J, Bridge J, et al. (1994) Personality disorder, personality traits, impulsive violence, and completed suicide in adolescents. J Am Acad Child Adolesc Psychiatry 33: 1080-1086.

31. Zhang Y, Feng $X$ (2011) The relationship between job satisfaction, burnout, and turnover intention among physicians from urban state-owned medical institutions in Hubei, China: A cross-sectional study. BMC Health Serv Res 11: 235

32. Wu H, Liu L, Wang Y, Gao F, Zhao X, et al. (2013) Factors associated with burnout among Chinese hospital doctors: a cross-sectional study. BMC Public Health 13: 786.

33. Inoue M, Tsukano K, Muraoka M, Kaneko F, Okamura H (2006) Psychological impact of verbal abuse and violence by patients on nurses working in psychiatric departments. Psychiatry Clin Neurosci 60: 29-36.

34. Vigoda E (2002) Stress-related aftermaths to workplace politics: The relationships among politics, job distress, and aggressive behavior in organizations. J Organ Behav 23: 571-591.

35. Sandi C, Haller J (2015) Stress and the social brain: Behavioural effects and neurobiological mechanisms. Nat Rev Neurosci 16: 290-304.
36. Johnson JG, Cohen P, Kasen S, Skodol AE, Hamagami F et al. (2000) Agerelated change in personality disorder trait levels between early adolescence and adulthood: A community-based longitudinal investigation. Acta Psychiatr Scand 102: $265-275$

37. Korenblum M, Marton P, Golombek H, Stein B (1987) Disturbed personality functioning: patterns of change from early to middle adolescence. Adolesc Psychiatry 14: 407-416.

38. Bernstein DP, Cohen P, Velez CN, Schwab-Stone M, Siever LJ, et al. (1993) Prevalence and stability of the DSM-III-R personality disorders in a communitybased survey of adolescents. Am J Psychiatry 150: 1237-1243.

39. Lenzenweger MF (1999) Stability and change in personality disorder features: the longitudinal study of personality disorders. Arch Gen Psychiatry 56: 1009 1015.

40. Drake RE, Vaillant GE (1988) Introduction: Longitudinal views of personality disorder. J Pers Disord 2: 44-48.

41. Stets JE, Straus MA (1989) The marriage license as a hitting license: A comparison of assaults in dating, cohabiting, and married couples. J Fam Vio 4: 161-180.

42. Melzer SA (2004) Gender, work, and intimate violence: Men's occupational violence spillover and compensatory violence. J Marriage Fam 64: 820-832. 